Annales Geophysicae (2001) 19: 99-114 C European Geophysical Society 2001

\title{
The SAO and Kelvin waves in the EuroGRIPS GCMS and the UK Met. Office analyses
}

\author{
M. Amodei ${ }^{1}$, S. Pawson ${ }^{2,3}$, A. A. Scaife ${ }^{4}$, U. Langematz ${ }^{5}$, W. Lahoz ${ }^{6}$, Ding Min Li ${ }^{4}$, and P. Simon ${ }^{1}$ \\ ${ }^{1}$ CNRM, Météo France, Toulouse, France \\ ${ }^{2}$ Data Assimilation Office, NASA GSFC, Greenbelt, MD, USA \\ ${ }^{3}$ Universities Space Research Association, Seabrook, MD, USA \\ ${ }^{4}$ The Meteorological Office, Bracknell, UK \\ ${ }^{5}$ Freie Universität Berlin, Germany \\ ${ }^{6}$ Center for Global Atmospheric Modelling, University of Reading, UK
}

Received: 12 May 2000 - Revised: 30 October 2000 - Accepted: 10 November 2000

\begin{abstract}
We compare the tropical oscillations and planetary scale Kelvin waves in four troposphere-stratosphere climate models and the assimilated dataset produced by the United Kingdom Meteorological Office (UKMO). The comparison has been made in the GRIPS framework "GCM-Reality Intercomparison Project for SPARC", where SPARC is Stratospheric Processes and their Role in Climate, a project of the World Climate Research Program. The four models evaluated are European members of GRIPS: the UKMO Unified Model (UM), the model of the Free University in Berlin (FUB-GCM), the ARPEGE-climat model of the French National Centre for Meteorological Research (CNRM), and the Extended UGAMP GCM (EUGCM) of the Centre for Global Atmospheric Modelling (CGAM). The integrations were performed with different, but annually periodic external conditions (e.g., sea-surface temperature, sea ice, and incoming solar radiation). The structure of the tropical winds and the strengths of the Kelvin waves are examined. In the analyses where the SAO (Semi-Annual Oscillation) and the QBO (Quasi-Biennal Oscillation) are reasonably well captured, the amplitude of these analysed Kelvin waves is close to that observed in independent data from UARS (Upper Atmosphere Research Satellite). In agreement with observations, the Kelvin waves generated in the models propagate into the middle atmosphere as wave packets, consistent with a convective forcing origin. In three of the models, slow Kelvin waves propagate too high and their amplitudes are overestimated in the upper stratosphere and in the mesosphere, the exception is the UM which has weaker waves. None of the modelled waves are sufficient to force realistic eastward phases of the QBO or SAO. Although the SAO is represented by all models, only two of them are able to generate westerlies between $10 \mathrm{hPa}$ and $50 \mathrm{hPa}$. The importance of the
\end{abstract}

Correspondence to: $\mathrm{M}$. Amodei

(marielle.amodei@meteo.fr) role played in the SAO by unresolved gravity waves is emphasized. Although it exhibits some unrealistic features, the EUGCM, which includes a parametrization of gravity waves with a non-zero phase speed, is able to simulate clear easterly to westerly transitions as well as westerlies with downward propagation. Thermal damping is also important for the westerly forcing in the stratosphere.

Key words. Meteorology and atmospheric dynamics (middle atmosphere dynamics; tropical meterology; waves and tides)

\section{Introduction}

In recognition of the role of the middle atmosphere in climate, the World Climate Research Programme (WCRP) have initiated the project "Stratospheric Processes and their Role in Climate" (SPARC). The objectives of SPARC (WCRP 1993, 1998) are to investigate the mechanisms through which the middle atmosphere exerts an influence on climate, and to comprehensively examine Middle Atmosphere Climate Models (MACMs). This examination is being performed by the "GCM-Reality Intercomparison Project for SPARC" (GRIPS), which has been split into several phases, each dealing with a different aspect of the problem. Phase 1 aims to evaluate basic aspects of the performance of MACMs, testing their abilities to represent the dominant features of the general circulation of the atmosphere and the mechanisms which maintain these features. An examination of the largescale climatological structure of 13 MACMs was presented by Pawson et al. (2000), where the full objectives of the project are described.

Here we document the performance of four of the GRIPS models in the tropical middle atmosphere. In particular, how well these models simulate the dominant low-frequency vari- 
ability of this region: the Quasi-Biennial and Semi-Annual Oscillations (QBO and SAO). The four models discussed are: (i) the ARPEGE-climat model, developed at the French National Centre for Meteorological Research (CNRM); (ii) the Extended UGAMP general circulation model (EUGCM) developed by the Universities Global Atmospheric Modelling Project in the United Kingdom; (iii) the troposphere-stratosphere-mesosphere GCM from the Free University of Berlin (FUB-GCM); and, (iv) the Unified Model (UM) of the United Kingdom Met. Office (UKMO).

An ancillary issue is how (if at all) these oscillations are forced, which involves study of the higher frequency waves generated in the models. Here emphasis is placed on the wavenumber-1 Kelvin wave. A further objective of the study is to document these features in the assimilated dataset produced by the UKMO, originally in support of the Upper Atmospheric Research Satellite (UARS), as described in Swinbank and O'Neill (1994).

In the following section, a review is given of the dominant features of the tropical stratospheric circulation, with an emphasis on their main characteristics and the limited ability of models to represent them. Section 3 contains a description of the datasets from the four models and the UKMO assimilation. Section 4 contains the main results of the study. The paper ends with a summary and discussion sections.

\section{Tropical oscillations and their representation in models}

The QBO dominates the stratospheric winds in the lower to middle stratosphere and is detectable between 2 and $100 \mathrm{hPa}$ with a maximum amplitude near $10 \mathrm{hPa}$ (Hamilton, 1981). Alternating easterly and westerly wind regimes propagate downward, with the descent of easterly shear zones tending to propagate more slowly. QBO easterly winds typically reach $30 \mathrm{~m} / \mathrm{s}$, westerlies are weaker and reach $20 \mathrm{~m} / \mathrm{s}$. The oscillation is characterized by an irregular period varying from 22 to 36 months (e.g. Naujokat, 1986) and is confined to an equatorial band, with a half-width of about $15^{\circ}$ latitude.

Previous studies have shown different abilities of MACMs to represent the tropical oscillations. Pawson (1992) showed that no model could then simulate a QBO and that all models examined displayed a tropical windspeed located between the two peaks of the bimodal frequency distribution in observations. This means that neither phase of the QBO was represented at that time. Since the note of Pawson (1992), significant advances towards simulations of the QBO have been made, at least partly because of significant increases in our computational capacity.

It is generally accepted that the QBO is forced by upward propagating waves, along the lines proposed by Lindzen and Holton (1968) and Holton and Lindzen (1972). Recent modelling and experimental evidence (e.g. Horinouchi and Yoden, 1998; Dunkerton, 1997) shows that waves with a wide range of spatial scales contribute to the momentum budget of the QBO, which is a slight modification of the Holton and Lindzen (1972) model which invokes planetary scale tropical Kelvin and mixed Rossby-gravity modes as the momentum sources for the two phases of the QBO. Requirements for models to be able to capture these wave motions include an adequate vertical resolution to represent the shear zones and the vertical wavelengths as well as a generation mechanism for a tropical wave spectrum (e.g. Takahashi, 1996, 1999; Horinouchi and Yoden, 1998; Hamilton et al., 1999). QBO-like oscillations have been generated with high vertical resolution and the oscillations display strong vertical shears of the zonal wind. However, so far these simulations have either shown unrealistic features in the modelled climate or have oscillations with periods that are outside the observed range.

Lower stratospheric Kelvin waves were first detected by Wallace and Kousky (1968), using radiosonde records from three equatorial stations. The meridional wind associated with the Kelvin waves is zero while the zonal wind, the geopotential and the temperature perturbations are symmetric about the equator. Kelvin waves propagate eastwards. For waves propagating up into the stratosphere, the phase velocity is directed downwards, while the group velocity is directed upwards. In the presence of a vertical shear of the mean zonal wind, the vertical propagation of these waves is disturbed, and the vertical group velocity decreases to zero as the mean zonal wind approaches the phase speed of the waves. Dissipation of the waves then results in a net forcing on the zonal wind in the shear zone just below the critical line and the QBO or SAO eastward phase propagates downwards, but only if this forcing is sufficient to overcome the mean vertical advection by the upwelling Brewer-Dobson circulation (Kinnersley and Pawson, 1996; Dunkerton, 1991, 1997). Dissipation of Kelvin waves of the observed amplitude is insufficent to overcome the mean upwelling in the tropical stratosphere and gravity waves are likely to provide the deficit of forcing in reality (Dunkerton 1997). In the case of an easterly mean zonal wind, Kelvin waves are free to propagate and attain larger amplitudes as they reach greater altitudes. They break in the mesosphere, reduce the easterly wind speed and contribute to its reversal. Thermal damping is important for the slow Kelvin waves that do not encounter a critical level.

Deep convection, particularly active in the tropics is thought to be one of the main sources of the observed waves. Using a simplified model forced only by latent and convective heating Manzini and Hamilton (1993) found that latent heat release is by far the dominant excitation mechanism for Kelvin waves. Similarly, Hayashi and Golder (1994) proposed that equatorial waves result from wave-convection interactions and are intermittently triggered by random pulses of convective heating. Bergman and Salby (1994) used synoptic global cloud imagery from satellites to force the linearized primitive equations. Planetary-scale waves with periods longer than two days dominate the spectrum in geopotential. However, high-frequency gravity waves are also evident and although they have a smaller variance, they carry a 
larger fraction of the upward momentum flux.

In the LIMS (Limb Infrared Monitor of the Stratosphere) data Hitchman and Leovy (1988) showed that the Kelvin waves seem to be excited by isolated events in the troposphere and propagate into the middle atmosphere as wave packets. Their amplitude increases with height and when the zonal wind has a strong westerly shear with height it can reach $4-5 \mathrm{~K}$ at $2 \mathrm{hPa}$ during east-west SAO transitions and $3-4 \mathrm{~K}$ at $10 \mathrm{hPa}$ during the east-west QBO transitions. In their analysis of a 15-year long radiosonde record collected in Singapore $\left(1^{\circ} \mathrm{N}, 104^{\circ} \mathrm{E}\right)$, Shiotani and Horinouchi (1993) also noted a strong correlation between the Kelvin wave activity and the zonal wind acceleration as the QBO eastward phase descends. More recently, the data obtained by instruments onboard UARS confirmed the presence of Kelvin waves, although they were generally weaker than in the LIMS and radiosonde data. Their maximum amplitude is $2 \mathrm{~K}$ in the lower stratosphere and reaches $3 \mathrm{~K}$ between 5 and $1 \mathrm{hPa}$ (Canziani and Holton, 1994; Shiotani et al., 1997). These various observations also reveal that depending on the altitude, Kelvin waves have been detected with zonal wavelengths ranging from $30000 \mathrm{~km}$ to $40000 \mathrm{~km}$ (wave numbers 1 and 2), vertical wavelengths from 6 to $33 \mathrm{~km}$, periods from 4 to 20 days and phase velocities from 23 to $115 \mathrm{~m} / \mathrm{s}$. They are observed where winds are easterlies or weak westerlies. They are amplified by both increasing altitude and strong west wind shear associated with the QBO or SAO. Under these conditions, they are more easily detected although their amplitude is weaker in the lower stratosphere and their activity varies over the course of the year as they seem to be episodically excited.

The stratopause SAO was discovered by Reed (1966) and described in some detail by Hirota (1980). The SAO is an oscillating wind structure which dominates the variance between about $1 \mathrm{hPa}$ and $0.1 \mathrm{hPa}$ (the mesopause SAO is a downward propagating signal out-of-phase with the stratopause SAO). A comprehensive climatology of the stratopause SAO was compiled from a variety of observations by Garcia et al. (1997). As with the QBO, the generation of westerly winds requires a wave-mean flow interaction. Rocket and satellite observations show that high phasespeed Kelvin waves do indeed propagate into the mesosphere and, along with gravity-waves, are involved in the downward-propagating westerly acceleration (Hirota, 1978; Hitchman and Leovy, 1988). The mechanism driving the SAO westward phase is completely different. The occurrence of simultaneous accelerations in a deep layer suggests that the source is not an interaction of vertically propagating waves with the mean flow. Mahlman and Umscheid (1984) verified with a high-resolution general circulation model that the easterly acceleration was in fact due to meridional advection of easterlies onto the equator. This advection is driven by planetary-wave forcing and is stronger during northern than southern hemisphere winter, hence a stronger westward phase during January than July (Delisi and Dunkerton, 1988).

A problem detected in several MACMs (Hamilton and Mahlman, 1988; Sassi et al., 1993; Jackson and Gray, 1994;
Table 1. Summary of the temporal series studied

\begin{tabular}{|c|c|c|c|}
\hline $\begin{array}{l}\text { High frequen- } \\
\text { cy data }\end{array}$ & Frequency & Vertical domain & Latitudes \\
\hline UKMO UM & Every $6 \mathrm{~h}$ & $\begin{array}{l}\text { Interpolated on } \\
25 \text { pressure lev- } \\
\text { els from } 1000 \\
\text { to } 0.1 \mathrm{hPa}\end{array}$ & $\begin{array}{l}3^{\circ} 75 \mathrm{~N}, \\
1^{\circ} 25 \mathrm{~N}, 1^{\circ} 25 \mathrm{~S}, \\
3^{\circ} 75 \mathrm{~S}\end{array}$ \\
\hline $\begin{array}{l}\text { FU-Berlin } \\
\text { FUB-GCM }\end{array}$ & Every $4 \mathrm{~h}$ & $\begin{array}{l}\text { Interpolated on } \\
27 \text { pressure lev- } \\
\text { els from } 1000 \\
\text { to } 0.01 \mathrm{hPa}\end{array}$ & $2^{\circ} 8 \mathrm{~N}-2^{\circ} 8 \mathrm{~S}$ \\
\hline $\begin{array}{l}\text { Météo-France } \\
\text { (CNRM) } \\
\text { ARPEGE- } \\
\text { climat V2 }\end{array}$ & Every $6 \mathrm{~h}$ & $\begin{array}{l}\text { Interpolated on } \\
17 \text { pressure lev- } \\
\text { els from } 1000 \\
\text { to } 0.05 \mathrm{hPa}\end{array}$ & $2^{\circ} 8 \mathrm{~N}-2^{\circ} 8 \mathrm{~S}$ \\
\hline $\begin{array}{l}\text { CGAM } \\
\text { EUGCM }\end{array}$ & Every $6 \mathrm{~h}$ & $\begin{array}{lr}\text { On } 47 & \text { pressure } \\
\text { levels } & \text { from } \\
1000 \text { to } 0.01 \\
\mathrm{hPa}\end{array}$ & $1^{\circ} 4 \mathrm{~N}-1^{\circ} 4 \mathrm{~S}$ \\
\hline $\begin{array}{l}\text { UKMO Anal- } \\
\text { yses }\end{array}$ & $\begin{array}{l}\text { Every } \\
\text { Day } 12 \mathrm{~h} \\
\text { UTC }\end{array}$ & $\begin{array}{l}\text { Interpolated on } \\
19 \text { pressure lev- } \\
\text { els from } 1000 \\
\text { to } 1 \mathrm{hPa}\end{array}$ & $1^{\circ} 25 \mathrm{~N}-1^{\circ} 25 \mathrm{~S}$ \\
\hline
\end{tabular}

Norton and Thuburn, 1996; Müller et al., 1997) has been the inability to force westerly winds in the SAO. Jackson and Gray (1994) showed that inclusion of gravity waves with non-zero phase speeds, as are generated by tropical convection, gave an additional momentum source for the eastward phase of the SAO and corrected this bias. However, specification of these waves tends to have a detrimental impact on the westerly to easterly transition, which becomes a waveforced event (as with the QBO) rather than an advected feature (Manzini et al., 1997; see also Jackson and Gray, 1994). Although significant advances have been made, the importance of different forcing mechanisms for the SAO and the QBO is not yet fully understood.

\section{Data and methods}

\subsection{The models}

A comprehensive MACM output has been archived for the GRIPS model intercomparison (Pawson et al., 2000). A subset of these monthly mean data have been used to examine the large-scale structures of the tropical oscillations. For this study, these data have been supplemented with one year of high-frequency, three-dimensional model output from latitudes close to the equator to allow space-time spectral analysis, which is by now a standard technique for detecting tropical waves in three-dimensional datasets. There are some differences in the precise data used: the range of latitudes about the equator and the frequency of output differ from model to model; the main aspects of the datasets are summarized in Table 1. 
Table 2. Summary of the horizontal and vertical resolutions of the models

\begin{tabular}{lccccc} 
Model & Horizontal resolution & $\begin{array}{c}\text { Number } \\
\text { of levels }\end{array}$ & $\begin{array}{c}\text { Number of } \\
\text { levels between } \\
300 \text { and } 10 \mathrm{hPa}\end{array}$ & $\begin{array}{c}\Delta z(\mathrm{~km}) \\
\text { in lower strat. }\end{array}$ & $\begin{array}{c}\text { Top level } \\
\text { (hPa) }\end{array}$ \\
\hline UKMO & $\begin{array}{l}\text { Grid points } \\
\left(2^{\circ} 5 \times 3^{\circ} 75\right)\end{array}$ & 49 & 29 & 1.3 & 0.1 \\
UM & $\begin{array}{l}\text { Spectral T21 } \\
\left(5^{\circ} 6 \times 5^{\circ} 6\right)\end{array}$ & 34 & 9 & $2-3$ & 0.0068 \\
$\begin{array}{l}\text { FU-Berlin } \\
\text { FUB-GCM }\end{array}$ & & & & \\
Météo-France(CNRM) & $\begin{array}{l}\text { Spectral T21 } \\
\left(5^{\circ} 6 \times 5^{\circ} 6\right)\end{array}$ & 41 & 14 & 1.5 & 0.01 \\
ARPEGE-climat V2 & $\begin{array}{l}\text { Spectral T42 } \\
\left(2^{\circ} 8 \times 2^{\circ} 8\right)\end{array}$ & 47 & 12 & 1.3 & 0.01 \\
$\begin{array}{l}\text { CGAM } \\
\text { EUGCM }\end{array}$ & & & & & \\
\hline
\end{tabular}

The models used have different formulations and resolutions. Three of the models have spectral formulation. The ARPEGE-climat (Déqué et al., 1994; Bossuet et al., 1998) and FUB-GCM (Langematz and Pawson, 1997; Pawson et al., 1998) are run with triangular truncation at T21. The EUGCM (Jackson and Gray, 1994; Norton and Thuburn, 1996) was run at T42. The UM (Swinbank et al., 1998; Butchart and Austin, 1998) is a grid-point model with gridboxes of $3.75^{\circ} \times 2.5^{\circ}$ (longitude by latitude). All of the models employ a hybrid vertical coordinate with pure pressure levels above the upper troposphere. The vertical resolution and domain of the models is as high as was practical for climatological runs and is summarized in Table 2; all models have an upper boundary in the mesosphere. The number of levels between 300 and $10 \mathrm{hPa}, N_{300}^{10}$, gives some indication of the vertical resolution in the lower to middle stratosphere of the models, which ranges from about $2.5 \mathrm{~km}$ (FUB-GCM) to about $1.3 \mathrm{~km}$ (UM), but note that the spacing of levels generally changes with height.

All models include different parametrizations of sub-gridscale physical processes in the atmosphere. This includes the convection schemes, which are likely to be important for generating tropical waves, and gravity wave drag, which has a direct impact on the middle atmospheric circulation. In the ARPEGE-climate model, the parameterization of the effects of deep cumulus convection is based on a simple prediction of the convective mass flux, and a global traitment of the detrainment by relaxation of the large-scale values of the temperature and the moisture towards a single cloud profile (Bougeault, 1985). Both the UM and the UKMO assimilation also use a mass flux convection scheme with a representation of cloud ensemble characteristics and a stability dependent closure (Gregory and Rowntree, 1990). In the FUBGCM, the formation of clouds and precipitation due to small scale convection and its impact on the heat and moisture budget is parametrized by a scheme for deep penetrating cumulus convection (Kuo, 1974) and a second scheme for shallow, non-precipitating cumulus convection in the boundary layer (Tiedtke et al., 1988). The convective parameterization is quite different in the EUGCM and utilized a convectiveadjustement scheme. This scheme is essentially a lagged adjustement towards calculated reference profiles, where the profiles are based on the observed thermodynamic structure of the atmosphere in convective situations (Betts and Miller, 1993). Both the ARPEGE-climat and EUGCM include parametrizations of traveling gravity waves forced by convection, although these are based on quite different premises. In the EUGCM, a spectrum of gravity waves is parametrized following Jackson (1993) and Norton and Thuburn (1996), and a discrete spectrum of waves with fixed phase speeds is specified. The ARPEGE-climat model includes a parametrization of gravity waves excited by deep convection similar to the parametrization of orographic gravity waves of Palmer et al. (1986) which are also taken into account in the model. However, the source term of these convective gravity waves is modulated by the intensity of convective precipitation (Bossuet et al., 1998). The version of the UM used here also includes a representation of orographic gravity waves. The FUB-GCM does not include parametrized gravity wave effects. An important change to the FUB-GCM used in this study is that the version used here includes an improved treatment of longwave radiative transfer, which eliminates the unrealistic warm bias of the winter polar stratosphere of the previous model version.

\subsection{UKMO assimilated data}

The UKMO assimilated data (Swinbank and O'Neil, 1994) are daily global meteorological analyses. The data assimilation system is a development of the scheme used at the UKMO for operational weather forecasting, which has been extended to cover the stratosphere and has the potential to analyze a heterogeneous set of observational data (for example, NOAA satellite temperature profiles, radiosonde data, aircraft winds and temperatures). The assimilation system uses an almost identical version of the UM as was used for the simulations discussed here. The analyses have a vertical resolution in the stratosphere of approximately $1.6 \mathrm{~km}$. 


\subsection{Analysis techniques}

Due to of the dependence of wave generation and propagation on the background wind structure, profiles of the mean wind were used to help in the interpretation of the results. Time series of mean zonal winds were compared and used to help choose cases worthy of closer study.

Since we are examining Kelvin waves of planetary scale, all the models are able to capture their horizontal scales and time series of the vertical structure at any arbitrary longitude illustrate the vertical wavelengths and the phase propagation of the waves. From the dispersion relation for gravity (or Kelvin) waves, the group velocities can also be inferred from these plots. 90-day periods of the temperature field have been analysed at several altitudes. Quantitative estimates of the character of the waves have been obtained using space-time spectral analyses (Hayashi, 1982). This method allowed us to separate the spectral powers of eastward and westward travelling waves. The spectral power distribution, as a function of the zonal wave number and the frequency, can be compared to theoretical dispersion curves to identify the equatorial wave types present. The sampling frequency of the data must, of course, meet the conditions imposed by the spectral analysis. The temporal series used are sampled with frequencies that can isolate the Kelvin waves whose periods extend from 4 to 20 days.

\subsection{Statistical significance}

One year of data was analysed for this intercomparison. Due to atmospheric interannual variability, it is important to address the representativeness of the intercomparison. Any differences between the models can only be significant if they fall outside the range of interannual variability observed in any single model (or the atmosphere). To investigate the period of time necessary to provide statistically significant comparisons, a 10-year simulation of the ARPEGE-climat model has been analysed. To isolate spectral peaks associated with travelling equatorial waves, the spectral analysis was performed on overlapping 100-day time series centered on the 15th day of each month. The time series in Fig. 1 shows some interannual variability of the eastward spectral density of temperature for 12-day period waves. Power peaks occur more often during May and June, when an east-west shear in zonal wind is present between $5 \mathrm{hPa}$ and $30 \mathrm{hPa}$. In some years they occur in January and October. The differences in spectral peak intensity can be explained by the frequency of the occurence of the Kelvin wavetrains during the year. A comparison of time-height sections of temperature zonal wave 1 over the equator in the different years (not shown) shows that the wave amplitude is similar in each year. In addition, Fig. 1 shows that although the peak spectral power accurs at slightly different times during the year, most years show similar magnitude peak activity and one year is likely to be adequate to study the basic characteristics of the modelled Kelvin wave activity.

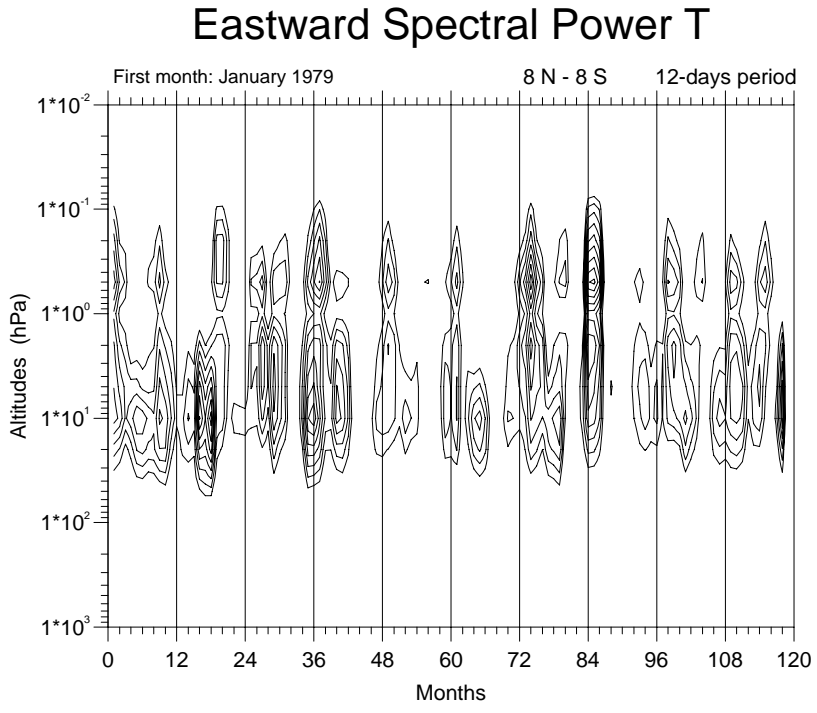

Fig. 1. Time series over 10 years of the spectral power of temperature fluctuations of zonal-wave number 1 and 12-day period during the period January 1979 to October 1988 . The contour interval is $1.5 \mathrm{~K}^{2}$ day. First contour is $7.5 \mathrm{~K}^{2}$ day. The power spectrum is defined as: $P_{k, \pm w}(A)=\frac{1}{2}\left[2\left|A_{k, \pm w}\right|\right]^{2} \Delta T$; where $A_{k, \pm w}$ is the complex space-time Fourier transform of the serie $A(x, t), k$ and $w$ are wavenumber and frequency and $\Delta T$ is the observationnal period.

\section{Results}

\subsection{Zonal wind and stratopause SAO}

Randel et al. (1999) showed that the QBO is reasonably well captured in the UKMO analyses; the main deficiency is that the extreme westerlies tend to be underestimated. A time series of the zonal-mean zonal wind near the equator (Fig. 2) shows the structures of both the QBO and SAO in the assimilated dataset, highlighting their different periodicities and amplitudes. Figure 2 also shows corresponding 4-year time series from the models. Recall that model year is arbitrary, since all of the models were integrated with climatological sea-surface temperatures, sea ice, and incoming solar radiation, all of which repeat from year to year. Clearly, none of these models represents a QBO, while all of them show a stratopause SAO, although the characteristics of these oscillations are quite different.

The FUB-GCM displays an oscillation between easterly and westerly winds in the lower mesosphere, but the westerlies rarely propagate below the stratopause (an exception is in the vernal equinox of the second year displayed). There is a strong oscillation between weak and strong easterlies, and some hint that both phases propagate downwards, suggesting a wave-forced regime, with more rapid dissipation in the decay phase than in the onset. There is also considerable interannual variability in this SAO simulation, slightly exceeding that in the previous version of the model (Müller et al., 1997), but note that the SAO westerlies were more realistic in the previous model version. 

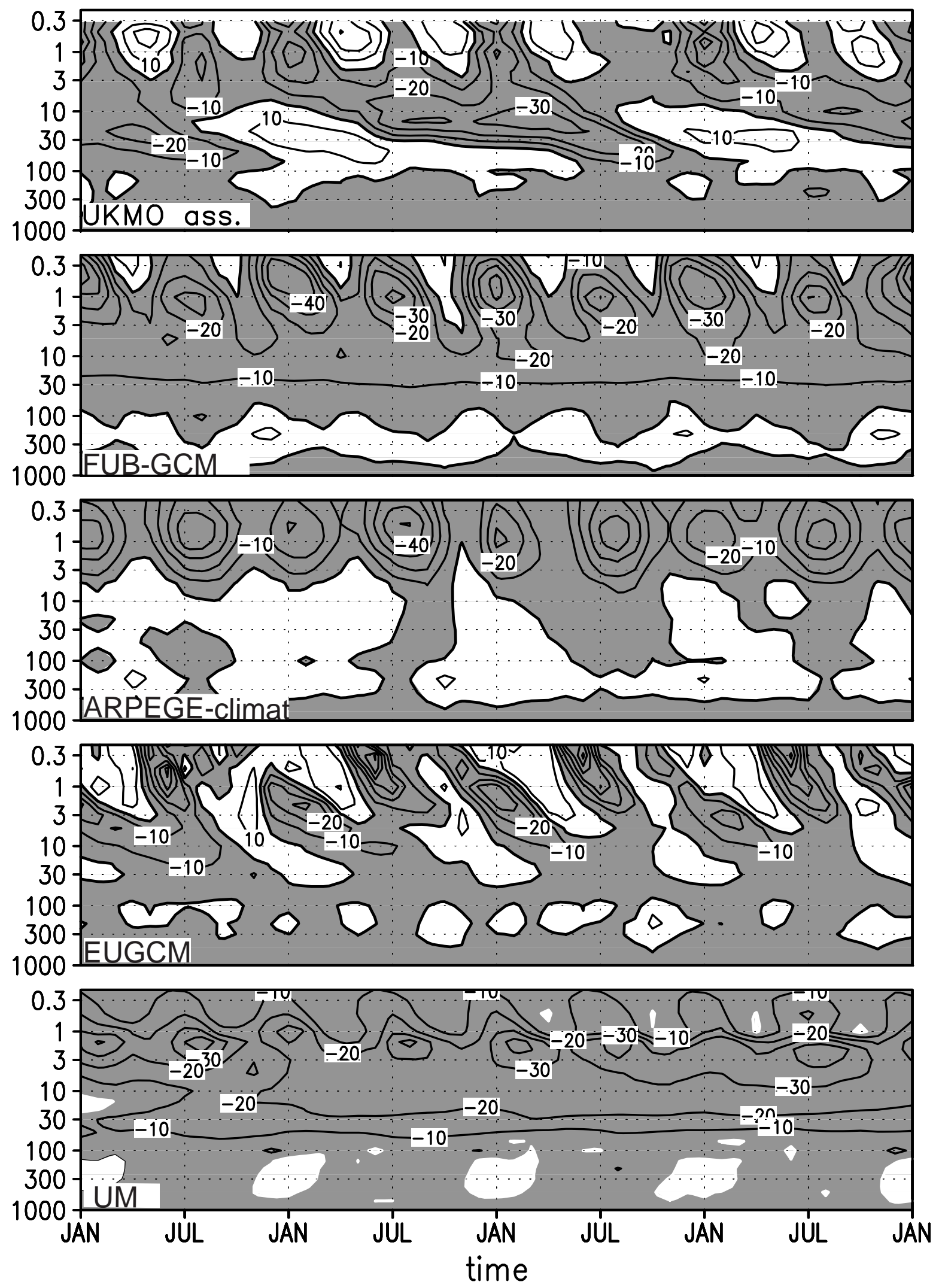

Fig. 2. Time series over four years of the zonal-mean zonal wind near the equator in the UKMO assimilated data and the FUB-GCM, ARPEGE-climat, EUGCM and UM models (top to bottom). Negative values (easterlies) are shaded and the contour interval is $10 \mathrm{~m} / \mathrm{s}$. The vertical axis extends from the surface to $0.2 \mathrm{hPa}$. The four selected years for the UKMO assimilated data are 1992 to 1996. 

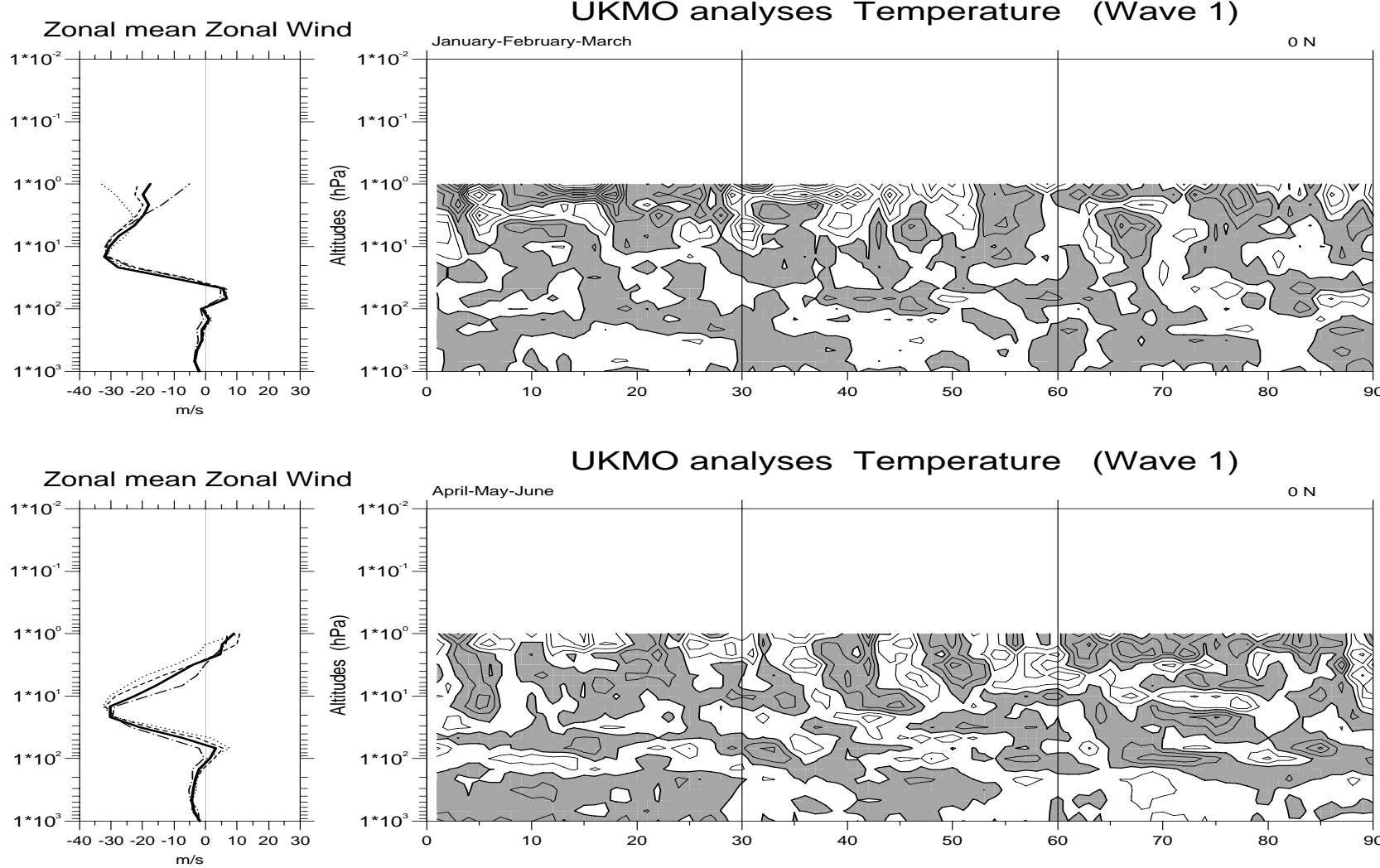

\section{UKMO analyses Temperature (Wave 1)}
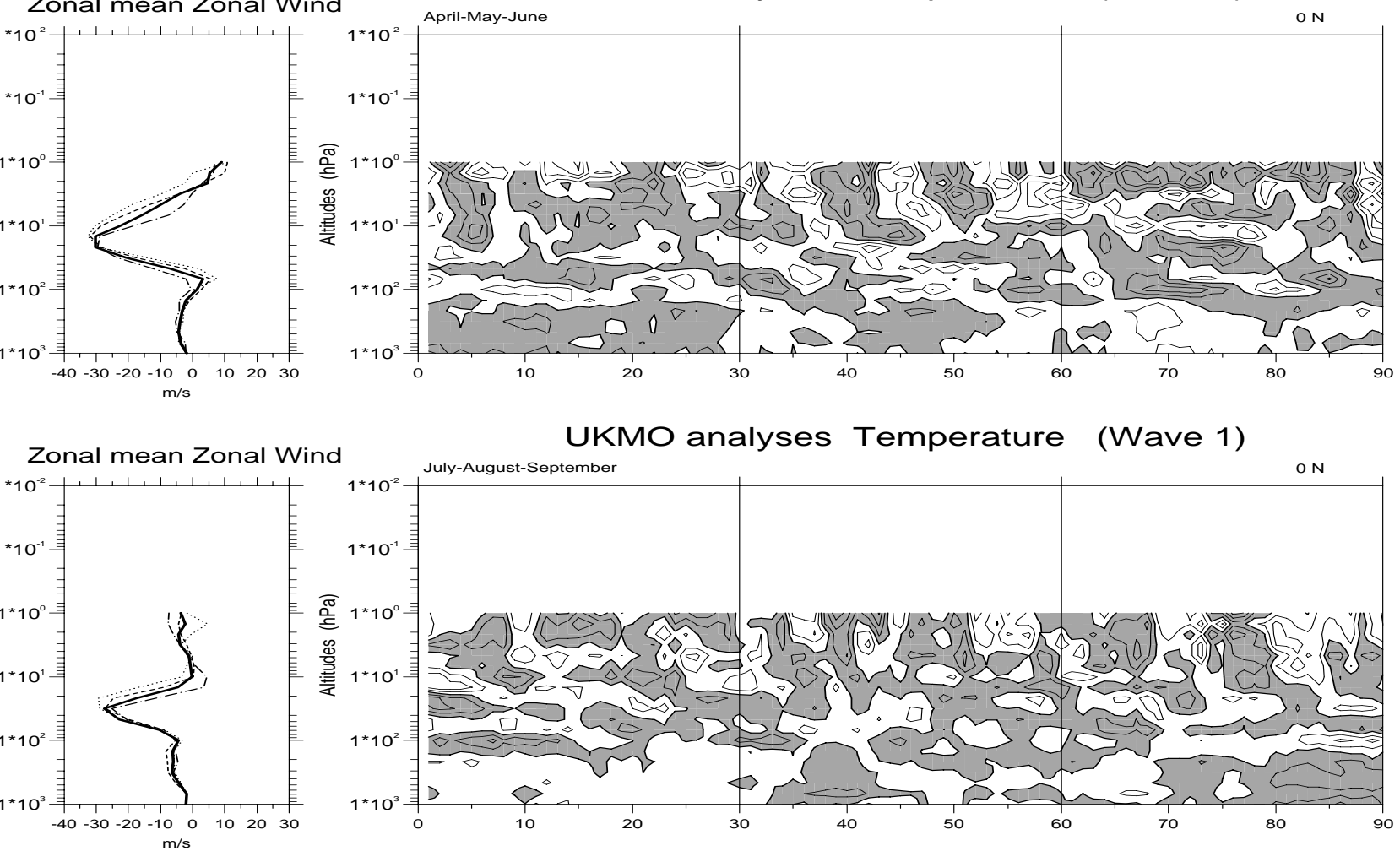

UKMO analyses Temperature (Wave 1)

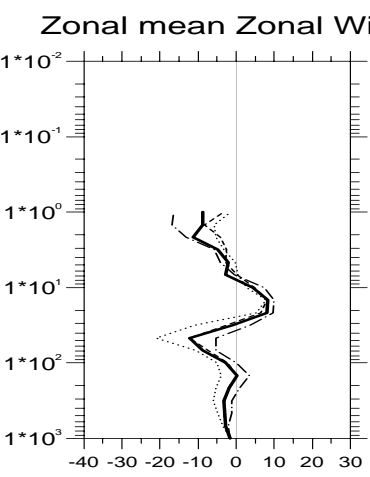

UKMO analyses Temperature (Wave 1)

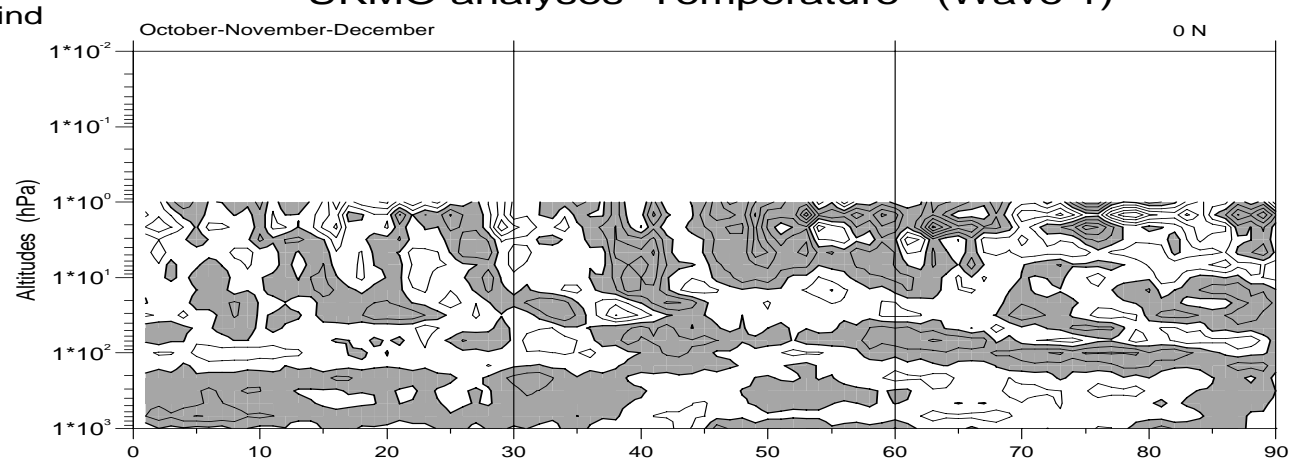

Fig. 3. Time-height section of temperature zonal wave 1 over the equator at $0^{\circ}$ longitude for the UK Met Office assimilated data for the year 1994. Positive values are shaded and the contour interval is $0.5 \mathrm{~K}$. The solid lines of the left panel show the zonal wind averaged over the 3 months of the right panels; dotted lines correspond to the first month, dashed lines to the second month and dash-dotted lines to the third month. 

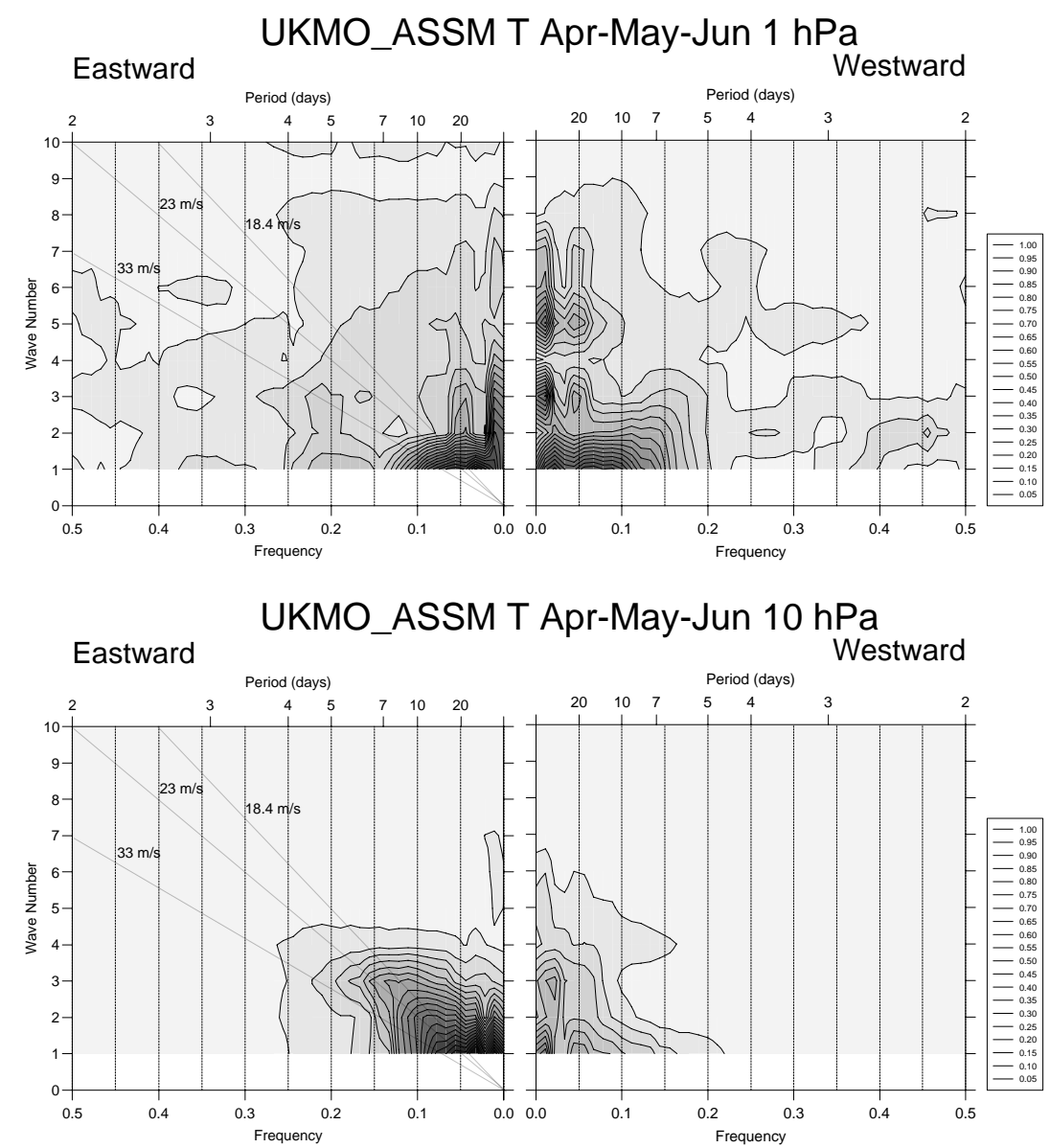

Fig. 4. Frequency-wavenumber power spectrum of the temperature field of the UK Met Office assimilated data, over the equator, for the time period April to June at $1 \mathrm{hPa}$ and $10 \mathrm{hPa}$. The contour interval is $0.05 \mathrm{~K}^{2}$ day. Solid lines are theoretical dispersion curves corresponding to different Kelvin waves phase speeds relative to the ground. The power spectrum is defined as in Fig. 1.

Both the ARPEGE-Climat and UM models show an oscillation between strong and weak easterlies in the stratopause region but no eastward phase. Unlike the observations, both of these simulations show stronger easterlies in July than in January, perhaps due to deficiencies in the simulation of extratropical planetary waves.

Although the SAO simulated by the EUGCM exhibits some unrealistic features in the stratosphere, it shows clear transitions from westerly to easterly winds near the stratopause; these are forced largely by imposed, parametrized gravity waves with non-zero phase speeds (Jackson and Gray, 1994). As in the model of Manzini et al. (1997), both phases of the simulated SAO in this model are induced by wave-forced descent of the shear layers, making the oscillation somewhat unrealistic in nature, despite the vacillation between easterlies and westerlies.

None of the models generates a QBO-like oscillation. In the UM and FUB-GCM the lower stratospheric winds are permanent easterlies. In the ARPEGE-Climat model, weak westerlies persist at these levels. In the EUGCM model, a westerly wind descent is initiated, but it has an annual period, weak amplitude and only descends to $30 \mathrm{hPa}$ or so.

\subsection{Kelvin waves in the UKMO assimilated data}

The UKMO assimilated data are sampled once daily (12Z ) on 19 levels distributed between 1000 and $1 \mathrm{hPa}$. The meridional resolution is $3.75^{\circ}$. Data were extracted for the year 1994, as during this period the QBO was in westward phase for the early part of the year and the eastward-westward transition of the SAO above $3 \mathrm{hPa}$ was prolonged by a descent of the QBO eastward phase. Figure 3 shows the temporal evolution of zonal wavenumber 1 and zonal-mean zonal wind profiles. The large shear of the wind with height and upwardpropagating wavetrains are apparent. The April-May-June (AMJ) period corresponds to the SAO eastward phase transition. The October-November-December (OND) period corresponds to onset and descent of the QBO eastward phase (Fig. 2). The data were Fourier analysed for each period.

For the AMJ period the temperature spectral power has been computed at two different levels (Fig. 4). While the zonal-mean zonal wind was easterly at $10 \mathrm{hPa}$, winds at $1 \mathrm{hPa}$ showed an SAO eastward phase with speeds reaching $15 \mathrm{~m} / \mathrm{s}$ 

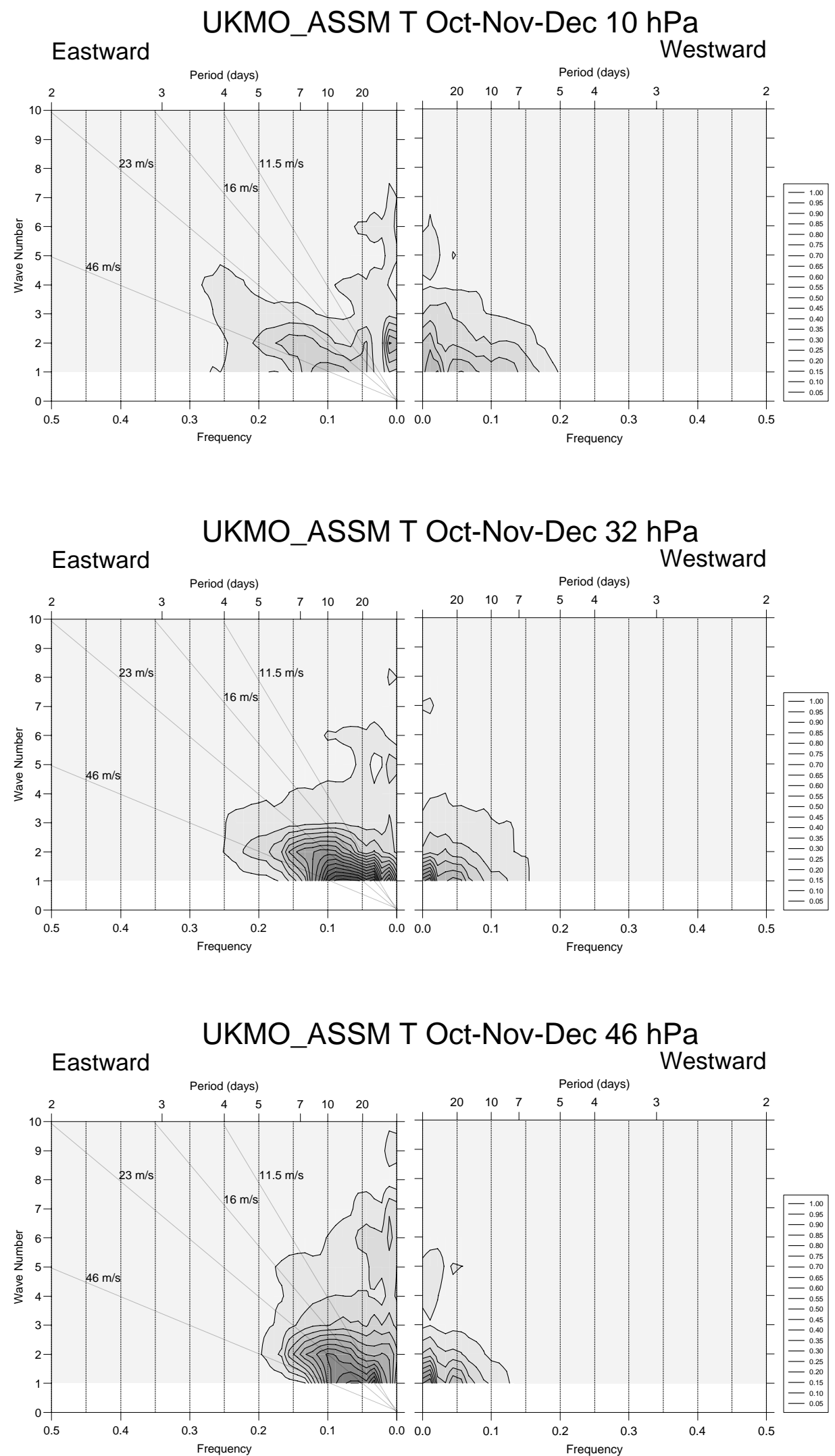

Fig. 5. Frequency-wavenumber power spectrum of the temperature field of the UK Met Office assimilated data, over the equator, for the time period October to December at $10 \mathrm{hPa}, 32 \mathrm{hPa}$ and $46 \mathrm{hPa}$. The contour interval is $0.05 \mathrm{~K}^{2}$ day. Solid lines are theorical dispersion curves corresponding to different Kelvin waves phase speeds relative to the ground. The power spectrum is defined as in Fig. 1. 

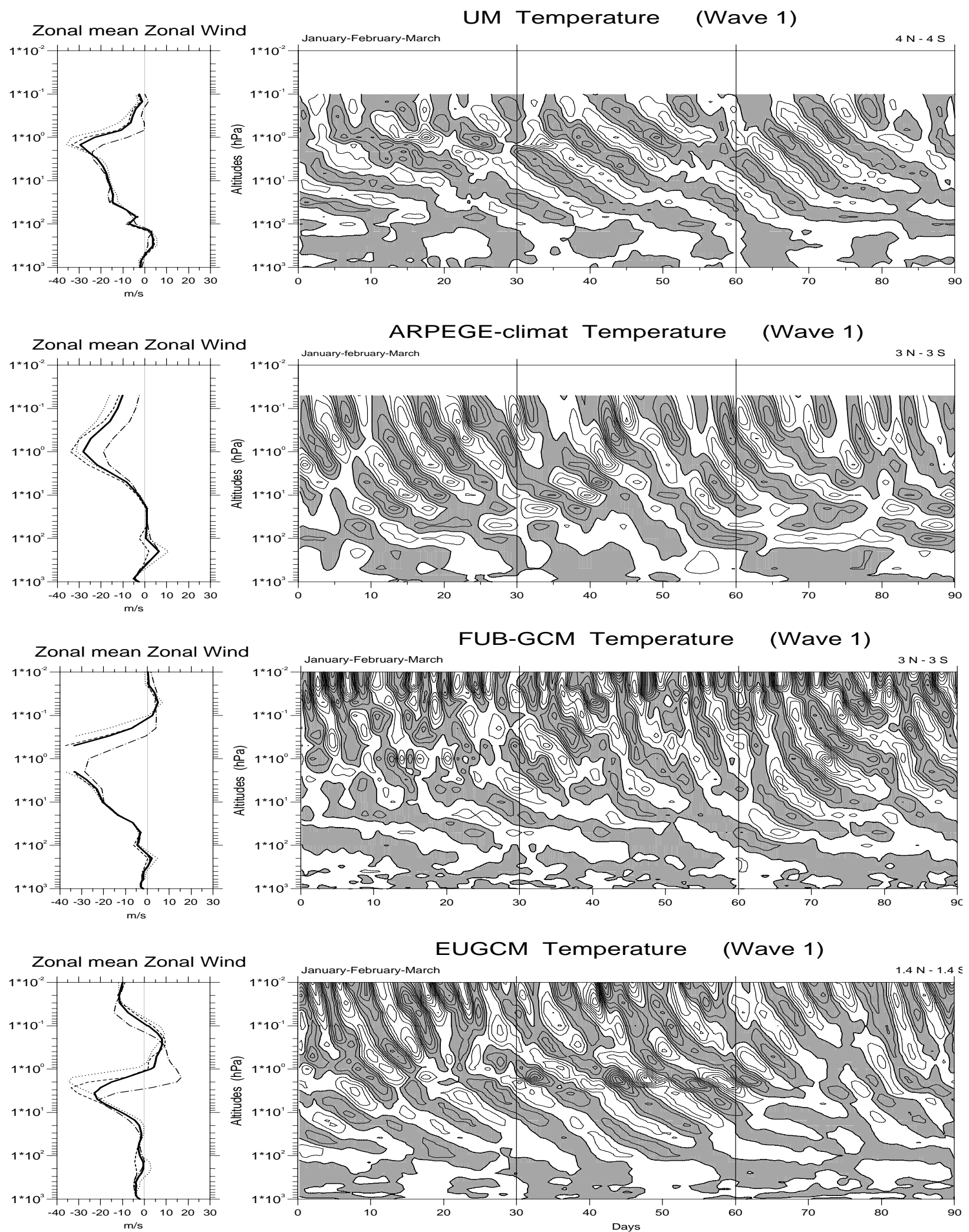

EUGCM Temperature (Wave 1)

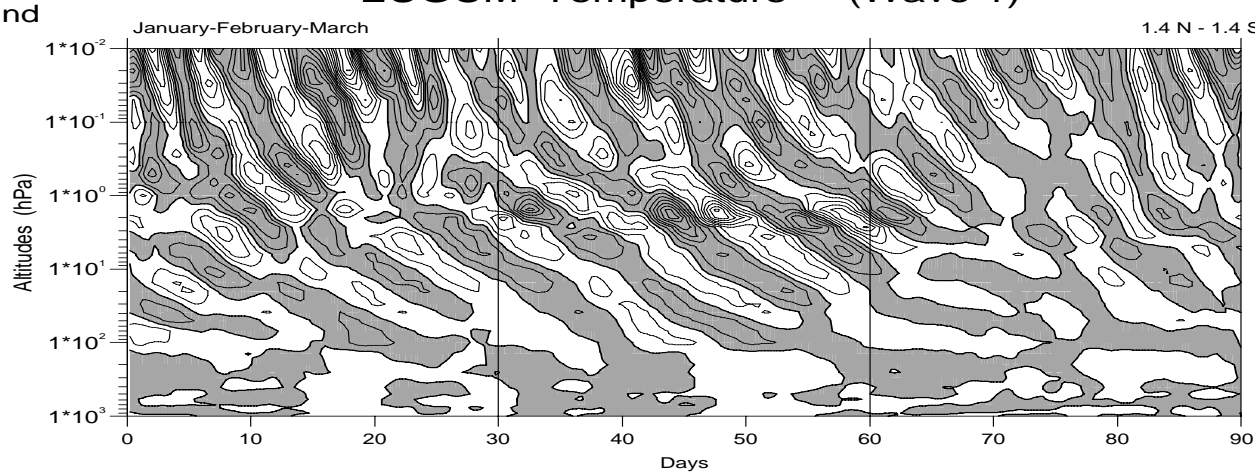

Fig. 6. Time-height section of temperature zonal wave 1 averaged over an equatorial band at $0^{\circ}$ longitude for the time period Jan-Mar and Apr-Jun for the UM, ARPEGE-climat, FUB-GCM and EUGCM models. Positive values are shaded and the contour interval is 1 K. The solid lines of the left panel show the zonal wind profiles averaged over the 3 months Jan-Feb-Mar and Apr-May-Jun; dotted lines correspond to January and April, dashed lines to February and May and dash-dotted lines to March and June. 


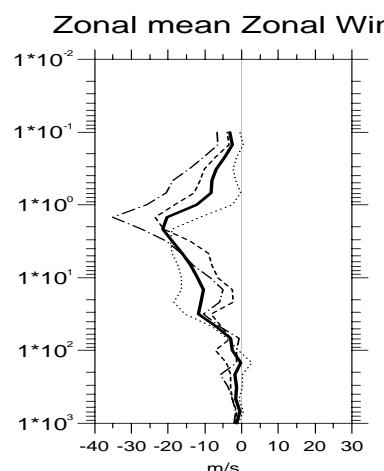

UM Temperature (Wave 1)
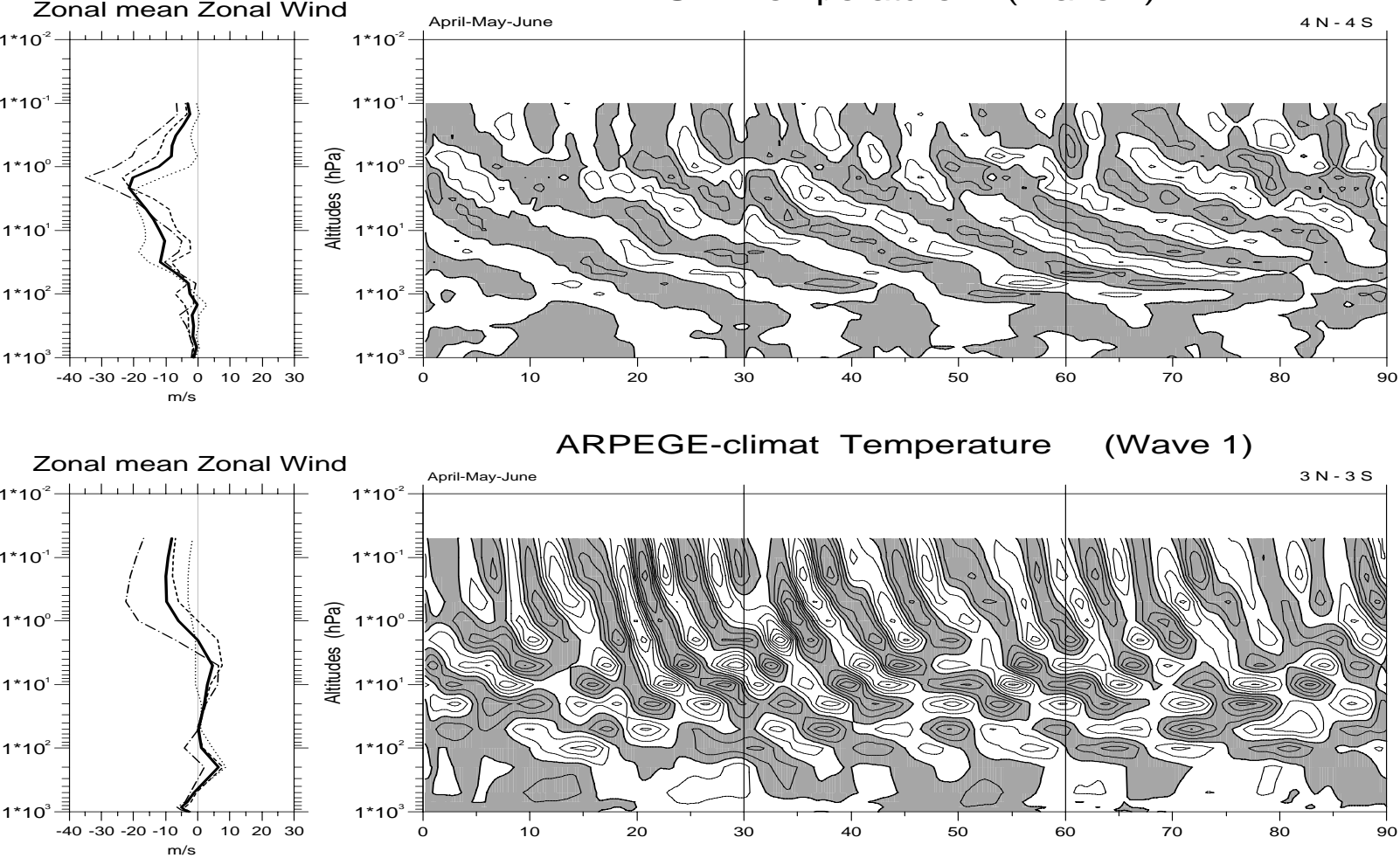

ARPEGE-climat Temperature (Wave 1)
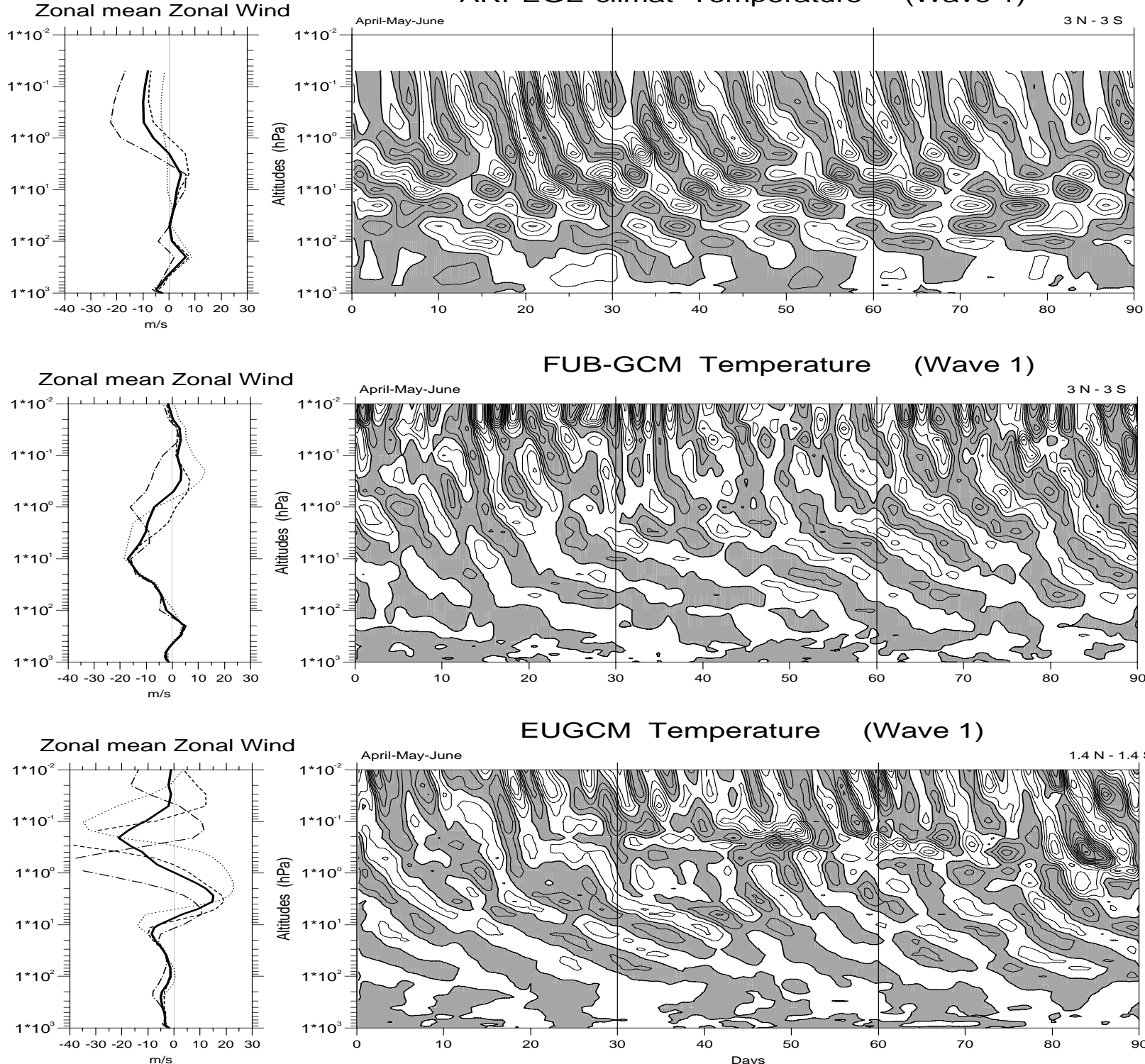

EUGCM Temperature (Wave 1)

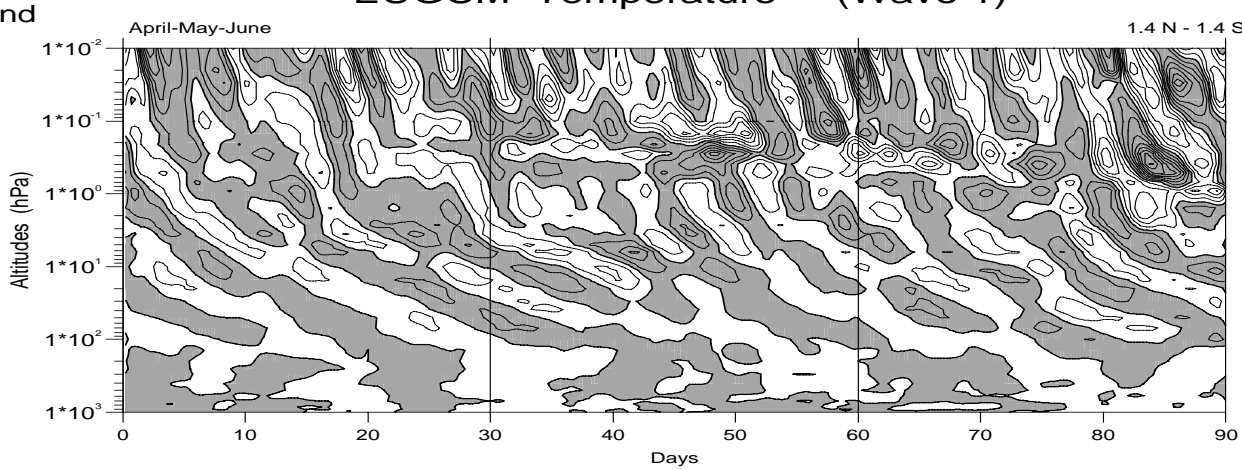

Fig. 6. continued. 
a)

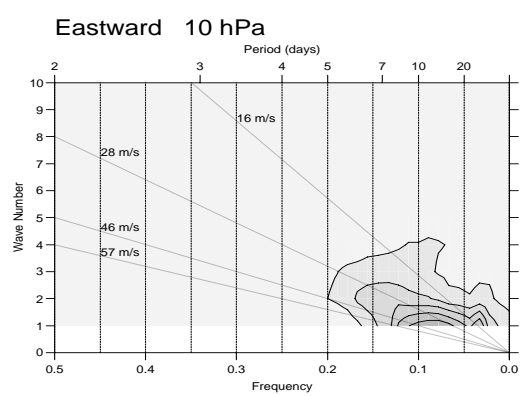

b)

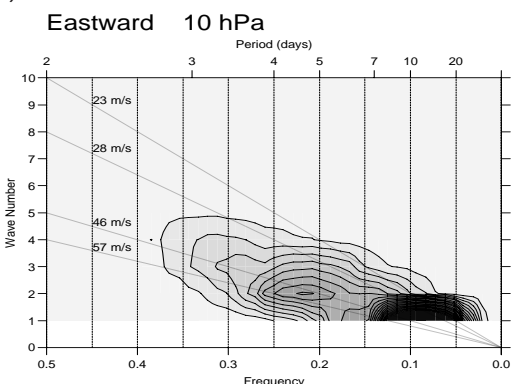

c)

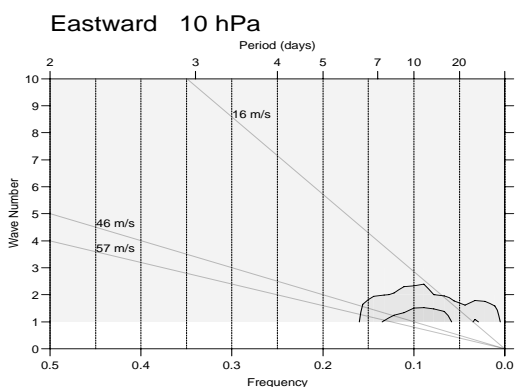

d)

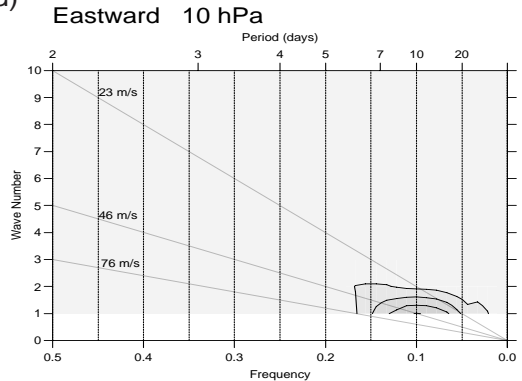

UM T Jan-Feb-Mar
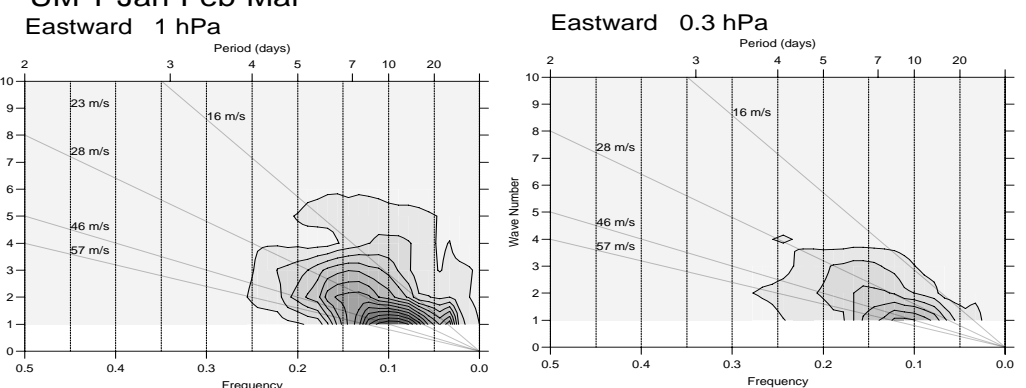

ARPEGE-climat T Apr-May-Jun
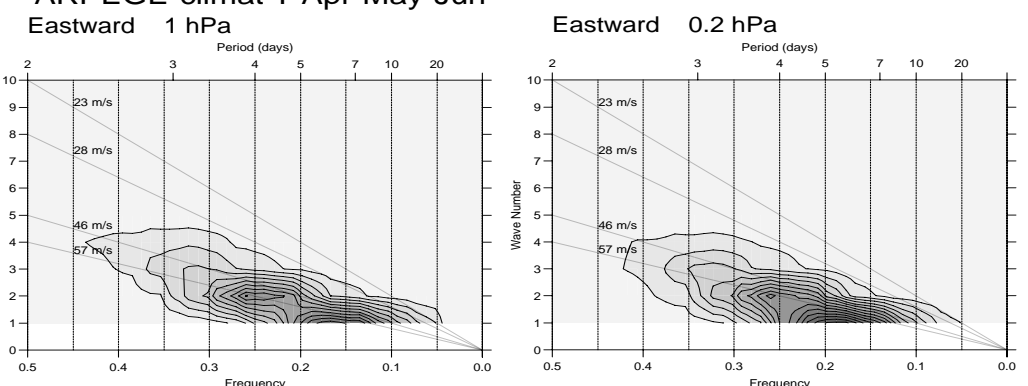
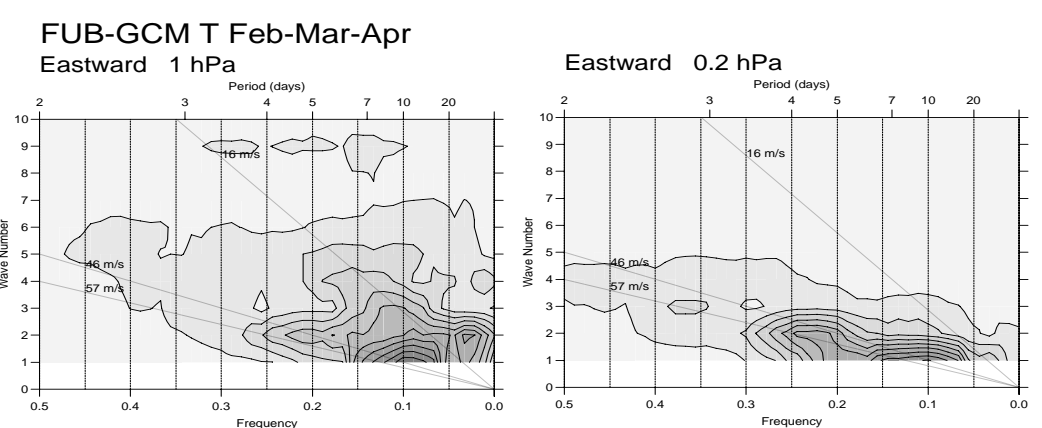

EUGCM T Jan-Feb-Mar

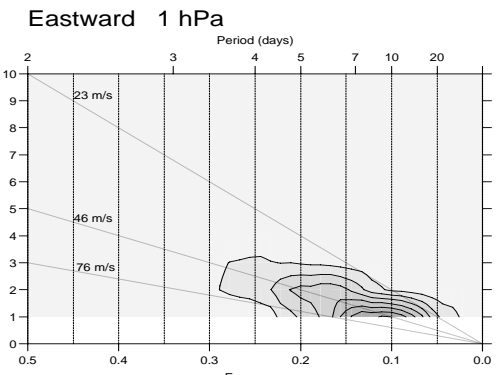

Eastward $0.3 \mathrm{hPa}$

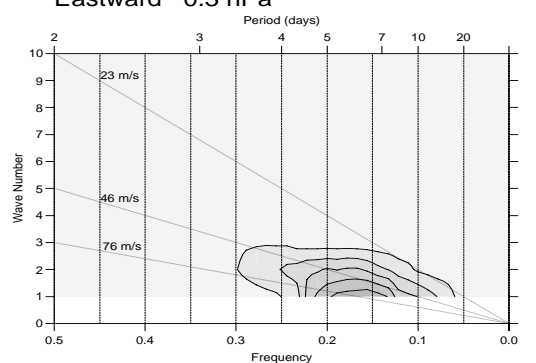

Fig. 7. Frequency-wavenumber power spectrum of the temperature field of the 4 models over an equatorial band. (a) UM model for the time period Jan-Mar at $10 \mathrm{hPa}, 1 \mathrm{hPa}$ and $0.3 \mathrm{hPa}$, (b) ARPEGE-climat model for the time period Apr-Jun at $10 \mathrm{hPa}$ and $1 \mathrm{hPa}$ and $0.2 \mathrm{hPa}$, (c) FUB-GCM for the time period Feb-Apr at $10 \mathrm{hPa}, 1 \mathrm{hPa}$ and $0.2 \mathrm{hPa}$, (d) EUGCM model for the time period Jan-Mar at $10 \mathrm{hPa}, 1 \mathrm{hPa}$ and $0.3 \mathrm{hPa}$. The contour interval is $1 \mathrm{~K}^{2}$ day. Solid lines are theoretical dispersion curves corresponding to different Kelvin waves phase speeds relative to the ground. The power spectrum is defined as in Fig. 1.

in May. The straight lines on these figures correspond to theoretical dispersion curves for Kelvin waves propagating in a stationary atmosphere. Eastward propagating waves with phase velocities of 33 to $18 \mathrm{~m} / \mathrm{s}$ are found at $10 \mathrm{hPa}$ and we interpret these as Kelvin waves. Some westward propagating waves are also present. The Kelvin waves are damped when they enter westerlies with speeds close to their own phase velocity, so that by $1 \mathrm{hPa}$ the waves are somewhat weaker but still exist. Figure 4 indicates that a rich spectrum of westward-propagating waves (dominant wavenumbers 1,3 , 
and 5, with low frequencies) also exists near $1 \mathrm{hPa}$.

Figure 5 displays the spectral power at $10 \mathrm{hPa}, 32 \mathrm{hPa}$ and $46 \mathrm{hPa}$ for the OND period. At $46 \mathrm{hPa}$, the zonal wind blows from the east over the whole period. Slow waves (11.5 to $16 \mathrm{~m} / \mathrm{s}$ ) as well as faster waves (23 to $46 \mathrm{~m} / \mathrm{s}$ ) are present at the same time. At $32 \mathrm{hPa}$ the zonal wind varies from 0 to $10 \mathrm{~m} / \mathrm{s}$ over the three months, reaching $15 \mathrm{~m} / \mathrm{s}$ locally. At $32 \mathrm{hPa}$, Fig. 5 shows that the spectral power is reinforced for waves with phase velocities ranging from 23 to $46 \mathrm{~m} / \mathrm{s}$. By $10 \mathrm{hPa}$, the slower waves have been attenuated and only fast waves are present.

All these figures reveal that in the lower stratosphere, eastward propagating waves have periods of 15 to 20 days and maximum amplitudes of around $2 \mathrm{~K}$. At $10 \mathrm{hPa}$ their periods are around 10 days and their amplitudes reach $2.5-3 \mathrm{~K}$. The results are in reasonable agreement with those from the UARS MLS data (Canziani and Holton, 1994) and the UARS CLAES data (Shiotani et al., 1997).

\subsection{Modelled Kelvin waves}

Upward propagating wavenumber-1 structures, identified as Kelvin waves, are clearly visible in the temperature field of all four models (Fig. 6). Their strength varies during the year and differs from model to model, but wavepackets generally occur more frequently than in the UKMO analyses or the UARS data. The synchronization between the downward propagation of the westerly winds maxima and the increase of the Kelvin wave amplitude is visible in all the models in the upper stratosphere, especially in the EUGCM model during April-June.

Consistent with the observations, these waves propagate vertically in packets and their vertical wavelength (and hence their pase velocity) increases with altitude. In the UM, this variation is relatively weak and over the February-March period the vertical wavelength remains practically constant over the whole stratosphere, with values smaller than for the other models.

The amplitude of the waves in the UM model, is closest to the observed value from UARS (Shiotani et al., 1997). It is of $1-2 \mathrm{~K}$ in the low stratosphere, where winds blow from the east and reaches $4 \mathrm{~K}$ in the high stratosphere during the periods January-March and August-October. These two periods corresponds to the acceleration of the SAO eastward phases. In the other three models, the Kelvin wave amplitudes reach 6-8 $\mathrm{K}$ in the high stratosphere where they exceed the observed amplitude. Amplitudes are 3-4 $\mathrm{K}$ in the low stratosphere, close to the wave amplitude observed by LIMS.

For each of the models, a period with strong Kelvin wave activity was chosen, associated either with a marked acceleration of the zonal wind or with a SAO eastward phase. These periods are January-March for the UM and EUGCM models, February-April for the FUB-GCM, and April-June for the ARPEGE-Climat. Figure 7 shows the temperature spectral power for three different levels in each model. For the selected periods eastward waves are predominant in the tem- perature field, so the westward power spectra has not yet been drawn in these cases.

Kelvin waves with small phase velocities $(16 \mathrm{~m} / \mathrm{s})$ are present in the UM and FUB-GCM models. The smaller phase speed waves are filtered as they reach high altitudes and westerly zonal winds ( $5 \mathrm{~m} / \mathrm{s}$ and $5-15 \mathrm{~m} / \mathrm{s}$, respectively). In agreement with both theory and observations, in three of the models (UM, FUB-GCM, EUGCM), the wave amplitude increases at around $1 \mathrm{hPa}$ in the presence of a strong acceleration of the zonal wind, before being attenuated in the levels immediately above $1 \mathrm{hPa}$. The zonal wave number $1 \mathrm{be}-$ comes strongly damped, particularly in the EUGCM model.

In the ARPEGE-Climat model, the maximum in the westerlies appears at $10 \mathrm{hPa}$ instead of $1 \mathrm{hPa}$ and the wind gradients remain weak between 10 and $40 \mathrm{hPa}$ (Figs. 6 and 7b). At $10 \mathrm{hPa}$, the zonal wind amplitude is 5 to $10 \mathrm{~m} / \mathrm{s}$ and zonal wave number 1 component of the temperature field is organised into pulses lasting for 7 to 20 days with amplitudes of 6 to $7 \mathrm{~K}$. The associated Kelvin waves have a phase velocity of 16 to $28 \mathrm{~m} / \mathrm{s}$ and are unable to propagate above $10 \mathrm{hPa}$.

\section{Discussion and conclusion}

The comparison between the stratospheric zonal winds in the tropics calculated by the four climate models reveals substantial differences. Nevertheless, an SAO is present in all models. The FUB-GCM reproduces easterly and westerly winds in the lower mesosphere, but the westerlies rarely propagate below the stratopause. In the UM and ARPEGE-climat models the SAO shows up as a semi-annual variation in the strength of the easterly winds. The simultaneous appearance of easterlies at all levels in the SAO in the three models is consistent with the observations, but the inter-annual variability is too weak compared to the UKMO assimilations. Note, that in contrast with observations, the easterly July phase is stronger than the January phase in the UM and ARPEGE-climat models. The SAO simulated in the EUGCM shows clear transitions from westerly to easterly winds near the stratopause. These are forced by imposed, parametrized gravity waves with non-zero phase speed. However, the westward phase displays some unrealistic features.

Unlike the other models, the ARPEGE-climat model has persistent westerlies between 1 and $10 \mathrm{hPa}$. The ARPEGEclimat model also uses a simplified scheme to predict the ozone distributions in the middle atmosphere (Cariolle and Déqué, 1986). The effects of ozone heating and photochemistry on forced equatorial Kelvin waves in shear flow have been examined by Echols and Nathan (1996). They showed that ozone heating produces an acceleration for a westerly sheared wind below $1 \mathrm{hPa}$ and a deceleration above $1 \mathrm{hPa}$. Note that the parametrization of gravity waves forced by convection included in this model has only small effects on the equatorial stratosphere.

None of the models reproduces wind structure that resembles the observed QBO. In the UM and FUB-GCM, between 10 and $40 \mathrm{hPa}$, winds are always easterly. The weak easter- 
lies in the FUB-GCM are typical for a model of that horizontal and vertical resolution without gravity wave drag parameterization. Scaife et al. (2000) show, using the latest version of the UM, that significant fluxes of both eastward and westward phase speed waves are resolved by the model. They noted a westward net forcing from these waves. In ARPEGEClimat, a weak westerly system exists at these levels, but without clear downward propagation although Cariolle et al. (1993) showed that the succession of easterly and westerly regimes in the zonal wind anomaly had a period and a downward propagation consistent with those of the observed QBO. The EUGCM initiates a realistic descent of the westerlies by about $1 \mathrm{~km} /$ month between 10 and $30 \mathrm{hPa}$, but the oscillation amplitude is too weak and it has an annual period.

In the assimilations, eastward and westward waves have similar amplitudes. The analyses also contain Kelvin waves with periods of 7 to 20 days and their amplitude is close to the amplitude observed by UARS. Slow 30-day waves are also present in the lower stratosphere. These waves are consistent with the linear theory of equatorial waves.

All four models studied here are able to generate Kelvin waves that appear to be excited by isolated tropospheric events and propagate into the middle atmosphere as wave packets. This suggests a relationship with sporadic convective forcing. The Kelvin wave amplitude is larger in the FUB-GCM, ARPEGE-Climat and EUGCM models, but remains comparable to the LIMS satellite data in the lower stratosphere. In the upper stratosphere and in the mesosphere, Kelvin waves are overestimated by these three models. They are close to the UARS satellite measurements in the UM model. All the models show more eastward propagating wave activity than the UKMO assimilated data.

To confirm the connection between the underlying convection and the wave activity emerging at tropopause level, we compared the convective rain field with the Kelvin wave activity in the 10-year simulation of the ARPEGE-climat model. Maximum eastward wave activity at $100 \mathrm{hPa}$ coincides with maximum rainfall during March and October over the Indian Ocean and April-May over Indonesia, the Pacific Ocean, America and Africa.

Westward propagating waves are superimposed on Kelvin waves in the UKMO analyses, which makes their detection more difficult. This is not the case in the models. Moreover, the zonal wind variability due to the presence of a QBO from the UKMO analyses perturbs the vertical propagation of Kelvin waves and favours the simultaneous presence of eastward and Westward waves. An interaction between these waves of opposite directions may also perturb the horizontal propagation of Kelvin waves. The conjunction of these two phenomena prevents Kelvin wavetrains from organizing. Due to the absence of a QBO in the models, Kelvin waves are not absorbed in the lower stratosphere and propagate up to the mesosphere where their amplitude grows so that they are overestimated in the upper stratosphere and mesosphere. They are not sufficient to force westerly winds at these levels, suggesting the importance of smaller scale waves.

Horinouchi and Yoden (1998) found that realistic struc- tures in cumulus convection generated by a scheme of Moist Convective Adjustment (MCA) were able to excite a complete range of waves, from small to planetary scales which are required to force the $\mathrm{QBO}$. MCA is also necessary to generate the spontaneous QBO in the GCM of Takahashi (1999) and the "QBO-like" oscillation in the GCM of Hamilton et al. (1999). MCA appears to generate more tropical waves than some of the more sophisticated convective parametrizations and this may account for the downward propagation of westerlies in the middle and lower stratosphere in the EUGCM. These authors mention also the importance of small enough vertical spacing $(500 \mathrm{~m}-700 \mathrm{~m})$ to resolve the small vertical wavelengths of waves approaching a critical level. Nissen et al. (2000) show that increasing the vertical resolution of the FUB-GCM leads to a more realistic Kelvin wave dissipation and the development of westerly winds in the model stratosphere. However, due to advection of strong easterly winds from the summer hemisphere, the eastward phase does not persist long enough. The dissipation of Kelvin waves at lower altitudes in the high resolution model version also leads to a weakening of the eastward phase of the SAO.

The results of the intercomparison are consistent with the view that a wide range of waves, especially small-scale waves not resolved by the models. A realistic convection scheme and an appropriate thermal damping are required for forcing the $\mathrm{QBO}$ and for the adequate generation of the SAO.

Acknowledgements. The model intercomparison has been funded by the European Framework IV "EuroGRIPS" Project (ENV4ST95-0123). MA is grateful to Anne De Rudder for her help in translating the original paper. She thanks Serge Planton, and Martine Michou for their useful comments on the manuscript. The FUB-GCM experiments were run at the Konrad-Zuse-Zentrum für Informationstechnik, Berlin.

Topical Editor D. Murtagh thanks two referees for their help in evaluating this paper.

\section{References}

Bergman, J. W. and Salbyk, M. L., Equatorial wave activity derived from fluctuations in observed convection, J. Atmos. Sci., 51, 3791-3806, 1994.

Betts, A. K. and Miller, M. J., The Betts-Miller scheme, in The representation of cumulus convection in numerical models of the atmosphere, Eds. K. A. Emanuel and D. J. Raymond, American Meteorological Society, 1993.

Bossuet, C., Déqué, M., and Cariolle, D., Impact of a simple parameterization of convective gravity-wave drag in a stratospheretroposphere general circulation model and its sensitivity to vertical resolution, Ann. Geophysicae, 16, 238-249, 1998.

Bougeault, P., A simple parameterization of the large-scale effects of cumulus convection, Mon. Wea. Rev., 113, 2108-2121, 1985.

Butchart, N. and Austin, J., Middle atmosphere climatologies from the troposphere-stratosphere configuration of the UKMO's unified model, J. Atmos. Sci., 55, 2782-2809, 1998.

Canziani, P. and Holton, J. R., Equatorial Kelvin waves: A UARS MLS view, J. Atmos. Sci., 51, 3053-3076, 1994. 
Cariolle, D. and Déqué, M., Southern hemisphere medium-scale waves and total ozone disturbances in a spectral general circulation model, J. Geophys. Res., 91, 10,825-10,846, 1986.

Cariolle, D., Amodei, M., Déqué, M, Mahfouf, J. F., Simon, P., and Teyssèdre, H., A quasi-biennial oscillation signal in general circulation model simulations, Science 261, 1313-1316, 1993.

Delisi, D. P. and Dunkerton, T. J., Seasonal variation of the semiannual oscillation, J. Atmos. Sci., 45, 2772-2787, 1988.

Déqué, M., Dreveton, C., Braun, A., Cariolle, D., The ARPEGE/IFS atmosphere model: a contribution to the French community climate modelling, Climate Dyn., 10, 249-266, 1994.

Dunkerton, T. J., Nonlinear propagation of zonal winds in an atmosphere with Newtonian cooling and equatorial wave driving, J. Atmos. Sci., 48, 236-263, 1991.

Dunkerton, T. J., The role of gravity waves in the quasi-biennial oscillation, J. Geophys. Res., 102, 26053-26076, 1997.

Echols R. S. and Nathan, R. R., Effects of ozone heating on forced equatorial Kelvin waves, J. Atmos. Sci., 53, 263-275, 1996.

Garcia, R. R., Dunkerton, T., Lieberman, R. S., and Vincent, R. A., Climatology of the semiannual oscillation of the tropical middle atmosphere, J. Geophys. Res., 102, 26019-26032, 1997.

Gregory, D. and Rowntree, P. R., A mass flux convection scheme with representation of cloud ensemble characteristics and stability dependent closure, Mon. Wea. Rev., 118, 1483-1506, 1990.

Hamilton, K., The vertical structure of the quasi-biennial oscillation: Observations and theory, Atmos. Ocean, 19, 236-250, 1981.

Hamilton, K. and Mahlman, J. D., General circulation model simulation of the semiannual oscillation of the tropical middle atmosphere, J. Atmos. Sci., 45, 3212-3235, 1988.

Hamilton, K., Wilson, R. J., and Hemler, R. S., Middle atmosphere simulated with high vertical and horizontal resolution versions of a GCM: Improvements in the cold pole bias and generation of a QBO-like oscillation in the Tropics, J. Atmos. Sci., 56, 38293846, 1999.

Hayashi, Y., Space-time spectral analysis and its application to atmospheric waves, J. Meteor. Soc. Japan, 60, 156-171, 1982.

Hayashi, Y. and Golder, D. G., Kelvin and mixed Rossby-Gravity waves appearing in the GFDL "SKYHI" general circulation model and the FGGE dataset: Implications for their generation mechanism and role in the QBO, J. Meteor. Soc. Japan, 72, 901935, 1994.

Hirota, I., Equatorial waves in the upper stratosphere and mesosphere in relation to the semiannual oscillation of the zonal wind, J. Atmos. Sci., 35, 714-722, 1978.

Hirota, I., Observational evidence of the semiannual oscillation in the tropical middle atmosphere - A review, Pure Appl. Geophys., 118, 217-238, 1980.

Hitchman, M. H. and Leovy, C. B., Estimation of the Kelvin wave contribution to the semiannual oscillation, J. Atmos. Sci., 45, 1462-1475, 1988.

Holton, J. R. and Lindzen, R. S., An updated theory for the quasibiennial cycle of the tropical stratosphere, J. Atmos. Sci., 29, 1076-1080, 1972.

Horinouchi, T. and Yoden, S., Wave mean flow interaction associated with a QBO-like oscillation in a simplified GCM, J. Atmos. Sci., 55, 502-526, 1998.

Jackson, D.R., Sensitivity of the extended UGAMP general circulation model to the specification of gravity-wave phase speeds, Quart. J. Roy. Meteor. Soc., 119, 457-468, 1993.

Jackson, D.R., and Gray, L.J., Simulation of the semi-annual os- cillation of the equatorial middle atmosphere using the extented UGAMP general circulation model, Quart. J. Roy. Meteor. Soc., 120, 1559-1588, 1994.

Kinnersley, J. S. and Pawson, S., The descent rates of the shear zones of the equatorial QBO, J. Atmos. Sci., 14, 1937-1949, 1996.

Kuo, H. L., Further studies of the parameterization of the influence of cumulus convection on the large scale flow, J. Atmos. Sci., 31, 1232-1240, 1974.

Langematz, U. and Pawson, S., The Berlin tropospherestratosphere-mesosphere GCM: Climatology and forcing mechanisms, Quart. J. Roy. Meteorol. Soc., 123, 1075-1096, 1997.

Lindzen, R. S. and Holton, J. R., A theory of the quasi-biennial oscillation, J. Atmos. Sci., 25, 1095-1107, 1968.

Mahlman, J. D. and Umscheid, L. J., Dynamics of the middle atmosphere: successes and problems of the GFDL "SKYHI" general circulation model, in Dynamics of the Middle Atmosphere, Eds. J. R. Holton and T. Matsuno, pp. 501-525, Terrapub, Tokyo, 1984.

Manzini, E. and Hamilton, K., Middle atmospheric travelling waves forced by latent and convective heating, J. Atmos. Sci., 50, 2180 2200, 1993.

Manzini, E., McFarlane, N. A., McLandress, C., Impact of the Doppler spread parameterization on the simulation of the middle atmosphere circulation using the MA/ECHAM4 general circulation model, J. Geophys. Res., 102, 25751-25762, 1997.

Müller, K. M., Langematz, U., and Pawson, S., The stratopause semiannual oscillation in the Berlin troposphere-stratospheremesosphere GCM, J. Atmos. Sci., 54, 2749-2759, 1997.

Naujokat, B., An update of the observed quasi-biennial oscillation of the stratospheric winds in the tropics., J. Atmos. Sci., 43, 1873-1877, 1986.

Nissen, K. N., Braesicke, P., and Langematz, U., QBO, SAO and tropical waves in the Berlin TSM GCM: Sensitivity to radiation, vertical resolution and convection, J. Geophys. Res., in press, 2000.

Norton, W.A. and Thuburn, J., The mesosphere in the Extended UGAMP GCM, in Gravity wave processes and their parametrization in global climate models, Ed. K. Hamilton, Springer-Verlag, 1996.

Palmer, T.N., Shutts, G.J. and Swinbank, R., Alleviation of a systematic westerly bias in general circulation and numerical weather prediction models through an orographic gravity wave drag parameterization, Q. J. Roy. Meteorol. Soc., 112, 10011039, 1986.

Pawson, S., A note concerning the inability of GCMs to model the QBO, Ann. Geophysicae lett., 10, 116-118, 1992.

Pawson, S., Langematz, U., Radek, G., Schlese, U., Strauch, P., The Berlin troposphere-stratosphere-mesosphere GCM: sensitivity to physical parameterizations, Q. J. Roy. Meteorol. Soc., 124, 1343-1371, 1998.

Pawson, S., Kodera, K., Hamilton, K., Shepherd, T. G., Beagley, S. R., Boville, B. A., Farrara, J. D., Fairlie, T. D. A., Kitoh, A., Lahoz, W., Langematz, U., Manzini, E., Rind, D. H., Scaife, A. A., Shibata, K., Simon, P., Swinbank, R., Takacs, L., Wilson, R. J., Al-Saadi, J. A., Amodei, M., Chiba, M., Coy, L., de Grandpré, J., Eckman, R. S., Fiorino, M., Grose, W. L., Koide, H., Koshyk, J. N., Li, D., Lerner, J., Mahlman, J. D., McFarlane, N. A., Mechoso, C. R., Molod, A., O’Neill, A., Pierce, R. B., Randel, W. J., Rood, R. B., and Wu, F., The GCM-Reality Intercomparison Project for SPARC (GRIPS): Scientific issues and initial results, Bull. Am. Meteorol. Soc., 81, 781-796, 2000. 
Randel, W. J., Wu, F., Swinbank, R. S., and O'Neill, A., Global QBO circulation derived from UKMO stratospheric analyses, J. Atmos. Sci., 56, 457-474, 1999.

Reed, R.J., Zonal wind behavior in the equatorial stratosphere and lower mesosphere, J. Geophys. Res., 71, 4223-4233, 1966.

Scaife, A., Butchart, N., Warner, C. D., Stainforth, D., Norton, W., and Austin, J., Realistic quasi-biennial oscillations in a simulation of the global climate, Geophys. Res. Lett., in press, 2000.

Shiotani, M. and Horinouchi, T., Kelvin waves activity and the quasi-biennial oscillation in the equatorial lower stratosphere, $\mathrm{J}$. Meteor. Soc. Japan, 71, 175-181, 1993.

Shiotani, M., Gille, J. C., and Roche, A. E., Kelvin Waves in the equatorial lower stratosphere as revealed by cryogenic limb array etalon spectrometer temperature data, J. Geophys. Res., 102, 26131-26140, 1997.

Sassi, F., Garcia, R. R., and Boville, B. A., The stratopause semiannual oscillation in the NCAR community climate model, J. Atmos. Sci., 21, 3608-3624, 1993.

Swinbank, R. and O'Neill, A., A stratosphere-troposphere data assimilation system., Month. Wea. Rev., 122, 686-702, 1994.

Swinbank, R., Lahoz, W., O'Neill, A. , Douglas, C. S., Heaps, A., and Podd, D., Middle atmosphere variability in the UK Met. Office Unified Model, Quart. J. Roy. Meteorol. Soc., 124, 14851525, 1998.

Takahashi, M., Simulation of the stratospheric quasi-biennial oscillation using a general circulation model, Geophy. Res. Lett., 23, 661-664, 1996.

Takahashi, M., Simulation of the quasi-biennial oscillation in a general simulation model, Geophys. Res. Lett., 26, 1307-1310, 1999.

Tiedtke, M., Heckley, W.A., and Slingo, J., Tropical forecasting at ECMWF: the influence of physical parametrisation on the mean structure of forecasts and analyses, Quart. J. Roy. Meteorol. Soc., 114, 636-666, 1986.

Wallace, J. and Kousky, V., Observational evidence of Kelvin waves in the tropical stratosphere, J. Atmos. Sci., 25, 900-907, 1968.

World Climate Research Program, Stratospheric processes and their role in climate: Initial review of objectves and scientific issues, WMO/TD-No. 582, WCRP-83, 1993.

World Climate Research Program, Stratospheric processes and their role in climate: Implementation plan, WMO/TD-No. 914 WCRP-105, 1998. 